\title{
FTK Students' Performance in Mathematics: Comparison between SPM and First Year Exam
}

\author{
Fadzilah Salim ${ }^{1, a}$, Aminah Ahmad ${ }^{1}$, Iskandar Waini ${ }^{1}$ and Nor Hamizah Miswan ${ }^{1}$ \\ ${ }^{1}$ FTK, Universiti Teknikal Malaysia Melaka, Hang Tuah Jaya, 76100 Durian Tunggal, Melaka, Malaysia
}

\begin{abstract}
In the last 20 years, mathematics teaching and learning encounters quite a big problem, especially at the tertiary level. The main concern always surrounds the students' achievement in the subject matter. Students' performance in mathematics at first year is reflected by the students' mathematical background prior to the admittance into the university. The study examined 165 first year students in the Faculty of Engineering Technology (FTK) who took the Mathematics Competency test upon entering the university at the beginning of their first semester. A test consisted of 40 fundamental mathematical questions which students have learned them before. From the result, $84 \%$ of these students failed this test. However, looking at their Sijil Pelajaran Malaysia (SPM) mathematics result during Form Five $\left(12^{\text {th }}\right.$ grade) in school, the majority did quite well in that exam. These students also took a first year mathematics course which is Technical Mathematics at the same semester. At the end of the semester, the result of their Technical Mathematics course seemed to be quite good. The performance of these three mathematics results was being compared and studied.
\end{abstract}

\section{Introduction}

Mathematics is a very important subject matter. It is used in our daily lives as well as it is taught at all academic institutions in the world; kindergartens, primary schools, secondary schools, pre-university colleges as well as at higher learning institutions. Even at home, among the first thing that is taught to a baby or a toddler is a counting number. However, since the last two decades, Mathematics teaching and learning seemed to face a lot of big challenges. Nowadays, the same scenario is happening to a lot of institutions of higher learning, be it in Malaysia or outside this country, the students' performance in this subject matter is being raised and questioned. This really the biggest concern, especially during the first year at the university [1].

There has been much research being studied on factors that affect students' performance in Mathematics at the tertiary level $[2,3,4]$. However, mathematical background of students entering the university, perhaps, is one of the key problems faced by the educators [1]. In a report released about the Trends in International Mathematics and Science Study (TIMSS) in 2011 among Grade 8 students in 42 participating countries, Malaysia's ranking in Mathematics fell from 16th (1999) to 10th (2003), 20th (2007) and 26th (2011). Similar patterns can also be seen in some other countries. This is very alarming

Studies made in the United States and Australia, both pointing to the instructors, classrooms and education environment for being among the factors affecting students' achievements in mathematics [5] beside other factors. However, it is undeniable that students' prior knowledge and academic achievement which result from students' prior cognitive mathematical ability influence very strongly in their mathematics achievements [6]. Students' secondary school mathematics background, not their university entrance score, has a spectacular consequence on pass rates [1]. Research shows that students hold remarkable perceptions regarding the knowledge of mathematics and science from the secondary school, that can influence considerably on the achievement of the mathematics courses at the university [7].

Mathematics can also be somewhat difficult to learn at times. It involves in applying formulae, using measurements, writing out phases of calculations, writing numbers, and spatial perception problems. A lot of understanding of the basic mathematical concepts and knowledge is required at the early stage of mathematical education. Students may easily get bored and dislike mathematics if they could not solve mathematical problems. However, the study made by Thien and Ong [8] found that Malaysian students loved studying Mathematics and they believed that mathematics is necessary for their future careers despite of their mathematics competency.

For this reason, mathematics educators play a very important role in ensuring students acquired a good grasp of the basic knowledge. What constitutes good mathematics teaching are having a very experienced educator who possesses comprehensive knowledge of

\footnotetext{
a Corresponding author: fadzilah@utem.edu.my
} 
mathematics, fosters mathematical comprehension, connects and inspires students, and entails successful management competence in mathematics [9].

\section{Methodology}

This study started with the collection of relevant information to investigate students' mathematics performance in SPM (Sijil Pelajaran Malaysia) examination, first year Mathematics Competency test and first year Technical Mathematics exam. The population was targeted to the first year university students in a Technical University in Malaysia, specifically at the Faculty of Engineering Technology or Fakulti Teknologi Kejuruteraan (FTK). In this study, the stratified sampling was used to obtain the sample. The sample consisted of 165 first year technical students enrolled in semester 1 , 2015/2016 academic year.

The data were collected from both secondary school and university sources. Data on students' secondary school were obtained from the student's past record. The students were asked to key in their results in google form. Meanwhile, the Mathematics Competency test results were obtained from the respective lecturers who had compiled the results previously, and first year Technical Mathematics exam results were extracted from the university database system.

The results for SPM mathematics were taken from Modern Mathematics exam, which is a compulsory subject taken by all SPM candidates. The topics learnt in this subject includes basic Statistics, Trigonometry and Algebra. The students' mathematics grades collected were based on a grade scale, ranging from A to F.

The Mathematics Competency test is a test taken by all first year university students to gauge their mathematics competency based on their prior knowledge. The main objective is to ensure that the students can continue their engineering or engineering technology studies smoothly because mathematics is the main foundation of this field. The test was executed at the beginning of the first semester first year, upon entering into the university. The test consisted of 40 questions to be answered in 90 minutes. There were 2 sections in the question paper. $50 \%$ of the questions were a combination of topics like basic functions, algebra and trigonometry, while another $50 \%$ of the questions were on calculus, such as basic derivatives and integrations. Students were not allowed to use any calculators during the test.

Technical Mathematics course, on the other hand, is the first out of four compulsory mathematics courses offered in the engineering technology faculty. The main course contents cover topics like algebra and trigonometry. The course is taught for 14 weeks of instructions with a breakdown of 28 hours lectures and 22 hours tutorials. The course work consists of 3 assignments worth 30\%, 1 mid-semester test worths $30 \%$ and 1 final exam worths $40 \%$, in which altogether make up to a total of $100 \%$ of the course marks. The result used in this study was the final exam results, which is the $100 \%$ total, obtained from the university database system.

\section{Results and Discussion}

The overall results of mathematics achievements are shown in Table 1 below.

Table 1. Percentage of Mathematics result performance.

\begin{tabular}{|c|c|c|c|}
\hline Grade & SPM (\%) & $\begin{array}{c}\text { Mathematics } \\
\text { Competency } \\
\text { Test (\%) }\end{array}$ & $\begin{array}{c}\text { Technical } \\
\text { Mathematics } \\
\text { course (\%) }\end{array}$ \\
\hline A+ & 43.75 & 0.00 & 0.00 \\
A & 40.63 & 0.00 & 34.38 \\
A- & 3.13 & 0.00 & 9.38 \\
\hline B+ & 9.38 & 0.00 & 9.38 \\
B & 0.00 & 0.00 & 15.63 \\
B- & 0.00 & 0.00 & 3.13 \\
\hline C+ & 0.00 & 15.63 & 3.13 \\
C & 3.13 & 0.00 & 12.50 \\
C- & 0.00 & 0.00 & 3.13 \\
\hline D+ & 0.00 & 0.00 & 3.13 \\
D & 0.00 & 0.00 & 6.25 \\
E & 0.00 & 84.38 & 0 \\
\hline
\end{tabular}

As depicted in Table 1 above, the highest percentage of mathematics performances for three different categories are an A+ grade for the SPM Modern Mathematics exam (43.75\%), an E grade for the first year Mathematics Competency test (84.38\%), and an A grade for the first year Technical Mathematics exam (34.38\%). In addition, the grading range of SPM result was from $\mathrm{A}+$ to $\mathrm{B}+$ and only a few students obtained a $\mathrm{C}$ grade. Based on the SPM result, we can conclude that students prior knowledge of mathematics during secondary school are very good. Surprisingly, Mathematics Competency test results showed otherwise. In fact, there were only two types of grades obtained by these students, that is, a C+ grade and an $\mathrm{E}$ grade. It shows that the majority of these students did very badly upon coming to the university. Approximately $84 \%$ of the students failed this test (E grade). However, at the end of the semester, all of them passed their first mathematics course which is Technical Mathematics. Their results were considered quite good.

One of the reasons why these results turned out the way they were, perhaps, the nature of the SPM exam is that the two years duration of mathematics learnt during Form Four and Form Five $\left(12^{\text {th }}\right.$ grade $)$ will be tested at the end of the two years of study. During this period, students had enough time to fully understand the subject matter. In other word, they would be able to make a good preparation for the SPM examination. Usually, students will be asked to do a lot of questions, exercises, and related problems which can also be the mathematics past years' questions, two or three months prior to this examination. Therefore, students were expected to do well in the SPM examination.

Basically, after the SPM results came out, students would be enrolled in either a pre-university or matriculation programme or Diploma programme. Most of the students entered their first year of a bachelor's degree programme in the university two or three years after the SPM examination. The Mathematics Competency test was carried out upon their admission to the university, that is, first year of a bachelor's degree programme, to see how well they could answer the 
fundamental questions of mathematics that they have learnt before. In other words, the university anticipates that the students should possess a certain level of mathematical knowledge prior to pursue their degree programmes. This is to prepare them for the mathematics and engineering technology courses at the degree level, so that, should there be any problems arise, some measures can be taken to help them to proceed smoothly and successfully in their studies. Unexpectedly, the majority of them failed this test, that is, $84 \%$ obtained $\mathrm{E}$ grades. Only a few of them, about $16 \%$ obtained $\mathrm{C}+$ grades. The feedback received was the majority of the students had forgotten what they had learnt before, even though the majority obtained good results in the SPM mathematics examination.

As for the Technical Mathematics results, this is quite a normal result obtained for any courses studied in a particular semester. In fact, this result can be considered quite a good achievement. This course runs every week for 14 weeks with a few assignments and one midterm test to help the students master the subject matter prior to the final examination. The breakdown assessments for the course is $60 \%$ course work, while final exam only carries $40 \%$ of the total course. By the time the students sat for the final examination, the knowledge of what they have been taught in that semester were still not forgotten. Thus, like any other courses, the final results normally would have a range of A to D. In this case, no one failed this course.

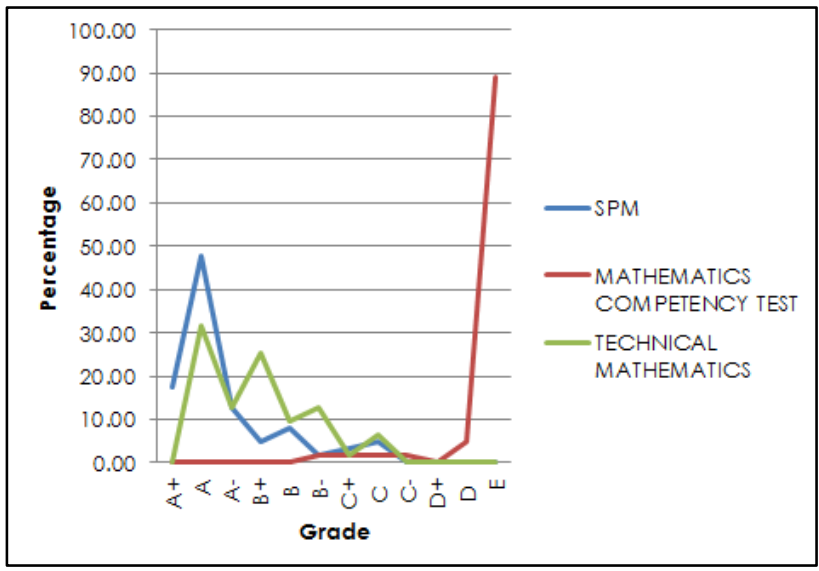

Figure 1. Line graph for mathematics performance comparison between SPM, Competency test and Technical Mathematics.

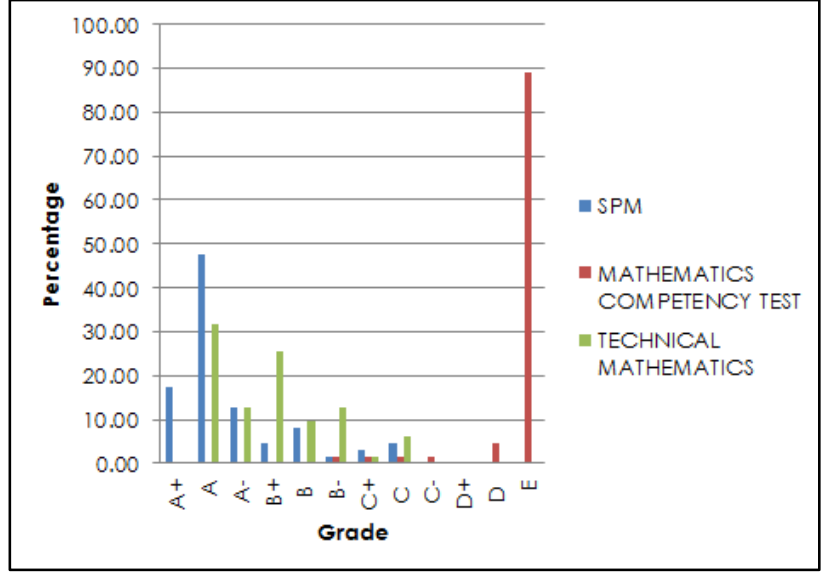

Figure 2. Histogram for mathematics performance comparison between SPM, Competency test and Technical Mathematics.

Figure 1 and Figure 2 shows the line graph and histogram of the mathematics performance in three categories respectively. The patterns show a very significant abnormalities in the first year Mathematics Competency test where the graph is skewed to the left with the line or bar to the further right shoot up very high. However, an approximate normal pattern was found for Technical Mathematics subject where the exam results were distributed between $\mathrm{A}$ to $\mathrm{D}$ grades.

The results also show a very significant difference between the Mathematics Competency test and SPM results. Most of the first year students obtained an E grade in their Mathematics Competency test and it was contradict to their SPM results. In SPM, most of them obtained $\mathrm{A}+$ grade. One of the reasons was that the students were trained to answer a lot of past years' SPM questions for a few months, right before the SPM examination. Their minds and memory were not being interfered by other stuff which might cause the recollection of memories of what recently taught would be gone [10], right before the examination. In contrast, the Mathematics Competency test was carried out upon entering the university which is after students had quite a long break in between. After the SPM examination, some students might enter a pre-university courses such as Matriculation program or STPM (Sijil Tinggi Persekolahan Malaysia) for two years, or Diploma program for three years before entering the university, still there are a few months gap before they enter the university. That is the main reason why the majority of the students failed the Mathematics Competency test which is due to the lost of short term memory of the mathematical knowledge learnt before. In other words, they have forgotten what they have been taught before.

Table 2. Mean and standard deviation of mathematics performance.

\begin{tabular}{|c|c|c|c|}
\hline & SPM & $\begin{array}{c}\text { Mathematics } \\
\text { Competency } \\
\text { Test }\end{array}$ & $\begin{array}{c}\text { Technical } \\
\text { Mathematics } \\
\text { course }\end{array}$ \\
\hline Mean & 3.62 & 0.23 & 3.04 \\
\hline
\end{tabular}




\begin{tabular}{|c|c|c|c|}
\hline $\begin{array}{c}\text { Standard } \\
\text { Deviation }\end{array}$ & 5.71 & 11.25 & 4.26 \\
\hline
\end{tabular}

Table 2 represents the mean and standard deviation of mathematics achievements based on SPM, first year Mathematics Competency test and first year Technical Mathematics examination results. These mean and standard deviation were calculated based on the grade point score for every grade in the grading system as shown in Table 3 below. From Table 2, the mean for SPM, first year Mathematics Competency test and first year Technical Mathematics exam results were 3.62, 0.23 and 3.04, respectively. For SPM result, the mean score suggests that the majority of the students obtained a range of A- to B+ grade, which is a very good achievement.

Meanwhile, the mean score of the Mathematics Competency test result suggests that the majority of the students failed this test because the value of the mean score would reflect to the range of D to E grade, which is a very bad result. However, the mean score for the Technical Mathematics result suggests that the majority was in the range of $\mathrm{B}$ to $\mathrm{B}+$, which shows a significant improvement after they have started to learn again the mathematics course, doing all the assignments and other course work, and sitting for the final examination at the end of the semester.

Table 3. A Standard grading system used in university in Malaysia.

\begin{tabular}{|c|c|}
\hline Grade & Point \\
\hline A + & 4.00 \\
A & 4.00 \\
A- & 3.67 \\
\hline B+ & 3.33 \\
B & 3.00 \\
B- & 2.67 \\
\hline C+ & 2.33 \\
C & 2.00 \\
C- & 1.67 \\
\hline D+ & 1.33 \\
D & 1.00 \\
E & 0.00 \\
\hline
\end{tabular}

\section{Conclusion}

Although having a sound mathematical knowledge at the secondary school is very crucial, other factors would also contribute to the successful achievement of students in mathematics and other mathematics related courses at the tertiary level. The main conclusion of this study is that based on the result of the Mathematics Competency test which was carried out upon admittance to the university, the majority of the first year students did not acquire sufficient knowledge in their basic mathematics during admission to the university. Therefore, the first impression to the mathematics educators at the tertiary level is that the basic mathematical knowledge of the majority of the students when they first enter the university are very poor. Thus, it is anticipated that the students may face some degree of difficulties in their future study in the university.

However, after investigating their SPM results, the perception of math educators towards students' background knowledge of mathematics contradicts with the Mathematics Competency test results. The majority of the first year students who entered the faculty of engineering technology possessed a very good result in Mathematics during their SPM examination. Thus, most of mathematics educators at the tertiary level have always questioned the validity and the reliability of the SPM results. Not to mention, some might wonder the way the mathematical subjects were being taught at schools. Then again, the results for Technical Mathematics course taken in the same semester shows that students' knowledge in mathematics has improved quite drastically.

The contradiction might happen because the students did not feel the essence of learning. Essence-based learning is unique in the way that it simultaneously addresses and triggers many important aspects of the learner's essential self: thinking, memory, emotions, ethics, aesthetics, the physical, and the senses. These factors personally and holistically engage the learner. All the factors must come together to produce great learner [11].

According to one of the five aspirations in Malaysian Education Blueprint (Higher Education) 2015-2025 [12], the government is very serious to improve the quality of education. Malaysia aimed to become the top $3^{\text {rd }}$ of countries in international assessment such as TIMSS and PISA (Program for International Student Assessment) in 15 years of time. The STEM (Science, Technology, Engineering and Mathematics) education has been emphasized. The national examination and assessments have been revised. The focus is now more on the level of higher-order thinking skills in STEM related subjects.

As a suggestion to the future study, there are still many areas that can be explored or researched further. One of them is the bridging knowledge that the students should acquire after SPM and before coming to the university. As mentioned before, most of the students will undergo a matriculation or pre-university programme before entering into the university. Thus, it will be interesting to compare their pre-university mathematics results prior to their entry into the university. Another interesting aspect that is worth to investigate is about the psychological effects like why many students nowadays can easily forget what they were being taught yesterday. There might be a few reasons which lead to the forgetfulness or short-term memory among students since they are being busy with many gadgets nowadays.

As part of the improvement strategy in teaching mathematics, researchers like Stigler and James [13] have looked into using the video survey to enhance the mathematics teaching and learning. Using technology in the teaching and learning Mathematics at the university may also help to better understand this subject matter [14]. However, Prins emphasized on the importance to consider the classroom size and students' preparedness before implementing any new style of teaching and learning [15]. Above all, studying the characteristics of students, teachers and school, educational aids and 
resources, as well as students' attitudes and motivation towards the learning of Mathematics would be essential in order to improve students' understanding and performance in Mathematics [16].

\section{Acknowledgement}

We wish to thank Universiti Teknikal Malaysia Melaka (UTeM), in particular, the Faculty of Engineering Technology for the help and support in carrying out the Mathematics Competency test for all the first year students last semester, i.e., semester 1, 2015-2016.

\section{References}

1. L. J. Rylands and C. Coady, "Performance of students with weak mathematics in first-year mathematics and science," Int. J. Math. Educ. Sci. Technol., vol. 40, no. 6, pp. 741-753, (2009).

2. H. Othman, I. Asshaari, N. M. Tawil, N. A. Ismail, Z. M. Nopiah, and A. Zaharim, "Analysis on Mathematics Fundamental Knowledge for Mathematics Engineering Courses based on a Comparative Study of Students' Entry Performance," Procedia - Soc. Behav. Sci., vol. 60, pp. 365-371, (2012).

3. P. Sastre-Vazquez, R. D. Andrea, Y. Villacampa, and F. J. Navarro-Gonzalez, "Do First-year University Students Understand the Language of Mathematics?," Procedia - Soc. Behav. Sci., vol. 93, pp. 1658-1662, (2013).

4. G. Anthony, "Factors influencing first-year students' success in mathematics," Int. J. Math. Educ. Sci. Technol., vol. 31, no. 1, pp. 3-14, (2000).

5. S. Lamb and S. Fullarton, "Classroom and school factors affecting mathematics achievement: A comparative study of Australia and the United States using TIMSS," Aust. J. Educ., vol. 46, no. 2, pp. 154-171, (2002).

6. J. Murray, "The Factors that Influence Mathematics Achievement at the Berbice Campus," Int. J. Bus. Soc. Sci., vol. 4, no. 10, pp. 150-164, (2013).

7. K. E. Matthews, P. Adams, and M. Goos, "Putting it into perspective: Mathematics in the undergraduate science curriculum," Int. J. Math. Educ. Sci. Technol., vol. 40, no. 7, pp. 891-902, (2009).

8. L. M. Thien and M. Y. Ong, "Malaysian and Singaporean students' affective characteristics and mathematics performance: evidence from PISA 2012," Springerplus, vol. 4, no. 1, p. 563, (2015).

9. P. S. Wilson, T. J. Cooney, and D. W. Stinson, "What constitutes good mathematics teaching and how it develops: Nine high school teachers' perspectives," J. Math. Teach. Educ., vol. 8, no. 2, pp. 83-111, (2005).

10. J. T. Wixted, "A theory about why we forget what we once knew," Curr. Dir. Psychol. Sci., vol. 14, no. 1, pp. 6-9, (2005).

11. A. Bokas and R, Rock. (2015, Feb 24). Edutopia [Online]. Available: http://www.edutopia.org/discussion/what-essence- learning

12. E. Summary, "Malaysia Education Blueprint $2013-$ 2025," Vasa, vol. 2025, (2012).

13. J. W. Stigler and J. Hiebert, "Improving Mathematics Teaching," Educ. Leadersh., vol. 61, no. 5, pp. 12 17, (2004).

14. Z. Lavicza, "The examination of technology use in university-level mathematics teaching," Proc. Symp. Occas., (2008).

15. S. C. Bates Prins, "Student-Centered Instruction in a Theoretical Statistics Course," J. Stat. Educ., vol. 17, no. 3, pp. 1-13, (2009).

16. N. A. Ismail and H. Awang, "Mathematics Achievement among Malaysian Students : What Can They Learn from Singapore?," Int. Educ. Stud., vol. 2, no. 1, pp. 8-17, (2009). 